\title{
Paraparetic variant of Guillain-Barré syndrome
}

INSERM

\section{Source}

INSERM. (1999). Orphanet: an online rare disease and orphan drug data base.

Paraparetic variant of Guillain-Barré syndrome. ORPHA:231445

Paraparetic variant of Guillain-Barré syndrome is a rare variant of Guillain-Barré

syndrome characterized by isolated leg weakness, areflexia and radicular leg pain that

may simulate a cauda equina or spinal cord syndrome. The arms, ocular, facial, and

oropharyngeal muscles are spared, and sphincteric function is normal. 